Correction

\title{
Correction: Liang, Y., et al. Short-Term Load Forecasting Based on Wavelet Transform and Least Squares Support Vector Machine Optimized by Improved Cuckoo Search. Energies 2016, 9, 827
}

\author{
Yi Liang ${ }^{1, *}$, Dongxiao Niu ${ }^{1}$, Minquan $\mathrm{Ye}^{2}$ and Wei-Chiang Hong ${ }^{3}$ \\ 1 School of Economics and Management, North China Electric Power University, Beijing 102206, China; \\ niudx@126.com \\ 2 School of Economics and Management, North China Electric Power University, Baoding 070000, China; \\ hdymq2014@163.com \\ 3 Department of Information Management, Oriental Institute of Technology, New Taipei 220, Taiwan; \\ samuelsonhong@gmail.com \\ * Correspondence: lianglouis@126.com
}

Academic Editor: Enrico Sciubba

Received: 10 November 2016; Accepted: 9 December 2016; Published: 16 December 2016

The authors wish to make the following corrections to their paper [1]:

Please add the sentence "However, seasonality and long-term trends of the proposed model have not been tested and verified in this paper, which may become the limitation of this method, and the authors intend to study this aspect in the future." behind "so it can be applied widely in parameter optimization." in the Conclusion section.

The authors would like to apologize for any inconvenience caused to the readers by this change. The change does not affect the scientific results. The manuscript will be updated and the original will remain online on the article webpage.

Conflicts of Interest: The authors declare no conflict of interest.

\section{Reference}

1. $\quad$ Liang, Y.; Niu, D.X.; Ye, M.Q.; Hong, W.-C. Short-Term Load Forecasting Based on Wavelet Transform and Least Squares Support Vector Machine Optimized by Improved Cuckoo Search. Energies 2016, 9. [CrossRef]

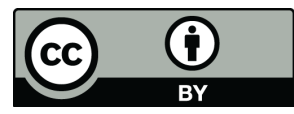

(C) 2016 by the authors; licensee MDPI, Basel, Switzerland. This article is an open access article distributed under the terms and conditions of the Creative Commons Attribution (CC-BY) license (http://creativecommons.org/licenses/by/4.0/). 